East African Medical Journal Vol. 83 No. 11 November 2006

MEDICOLEGAL AUTOPSIES IN NORTH CENTRAL NIGERIA

B.M. Mandong, MBBS, FMCPath, Professor and Consultant Pathologist, A.N. Manasseh, MBBS, FMCPath, Senior Lecturer and Consultant Pathologist, Department of Pathology and B.T. Ugwu, MBBCh, FWACS, Professor and Consultant Surgeon, Department of Surgery, Jos University Teaching Hospital, P.M.B. 2076, Jos, Nigeria

Request for reprints to: Dr. B.M. Mandong, P.O. Box 887, Jos, Plateau State, Nigeria

\title{
MEDICOLEGAL AUTOPSIES IN NORTH CENTRAL NIGERIA
}

\author{
B.M. MANDONG, A.N. MANASSEH and B.T. UGWU
}

\begin{abstract}
Objective: To determine the pattern and the causes of deaths reported to the coroner for medicolegal autopsies in North Central Nigeria.

Design: A descriptive retrospective study.

Setting: Jos University Teaching Hospital, Jos, Nigeria between January1996 to December 2003. Subjects: Autopsies reports of 279 subjects whose causes of death were subjects of litigation.

Main outcome measures: The causes of death in medicolegal autopsies.

Results: A total of 279 cases of medicolegal autopsies with identified causes of death were recorded representing $89 \%$ of all the autopsy examinations performed within the period. In $7.6 \%$ of cases, there was no identifiable cause of death. There were 127 males against 52 females with a male: female ratio of 4.5:1 and their ages ranged between two and 74 years with a mean of $34.7 \pm 8.2$ years. Children aged $<15$ years made up $29 \%$ of the cases and were distributed as follows: $4 \%$ of the children were aged 0-5 years, 9\% between six to ten years while $17 \%$ were between 11 - 15 years. Accidental deaths made up $51 \%$ of the cases, homicides $36 \%$ and sudden deaths $13 \%$. Road traffic accidents were responsible for $76 \%$ of all accidental deaths. Children were affected in $34 \%$ of the accidental deaths and half of them were pedestrians at the time of accident. The male: female ratio of deaths from road traffic accidents was 3:1 with mean age of 24 years. In all the accidental deaths, abdominal injuries were responsible for $47 \%$ while $30 \%$ died from chest injuries. Of the homicide cases male subjects outnumbered female in a ratio of $16: 1$ and children were affected in $28 \%$ of homicides. Injuries sustained during ethnic and religious crisis were responsible for $48 \%$ of the deaths from homicide and $15 \%$ of them were children. Armed robbery was responsible for $28 \%$ cases while physical assaults were responsible for $20 \%$ of homicides. Chest injuries were the causes of death in $54 \%$ and abdominal injuries in $36 \%$ of homicides. Cardiovascular deaths were responsible for $63 \%$ cases of all sudden natural deaths referred for Coroner's inquest during the period. Children made up $11 \%$ of all sudden natural deaths. Males outnumbered females in cardiovascular deaths in a ratio of $6: 1$ and $46 \%$ cases of them died of hypertensive heart failure, $32 \%$ had cerebrovascular accidents, pulmonary embolism in $13.6 \%$ and myocardial infarction in $\mathbf{9 \%}$. One case of myocardial infarction died during intercourse.

Conclusion: Road traffic accidents, violent communal unrest and armed robbery were responsible for $66 \%$ of the medicolegal autopsies in our environment. Public enlightenment, good road maintenance and safe driving culture as well as sustainable security for life and property would reduce the incidence of preventable deaths.
\end{abstract}

\section{INTRODUCTION}

Medicolegal autopsies are post mortem examinations performed at the instance of the law when a coroner is instructed to determine the cause, time and the circumstances of death. Medicolegal autopsies in Nigeria dates back to 1917 when the law stipulated that only sudden death that involved the European 
colonial masters were to be reported to the coroner for autopsy as reported in laws guiding births and deaths in Nigeria published in 1948 (1). However in 1945 , medicolegal autopsy was extended to every body in the country including the indigenous Nigerian population as reported in the Coroner's Laws of Northern Nigeria published in 1963 (2).

Other workers (3-5) in various parts of Nigeria had shown that the commonest causes of medicolegal autopsies were accidental deaths, followed by homicides and sudden natural deaths. Road traffic accidents is the commonest cause of accidental deaths in young people including the paediatric age group in various parts of Africa (3,58) from violent deaths in ethnic and religious clashes, assault and armed robbery are on the increase in Africa $(3,5,7,8)$. Suicide rates in medicolegal autopsies in the industrialised countries are high and this has been identified as a serious public health problem by the World Health Organisation (10) as opposed to the developing world where suicide rates are low $(2,11,12)$. Myocardial infarction is the commonest cause of sudden natural death in developed countries of Europe and America $(9,13,14)$ but the incidence is low in developing countries $(3,11,12,15)$. In order to determine the pattern and the causes of death in medicolegal autopsies in North Central Nigeria, we retrospectively studied 279 autopsy cases within an eight-year period.

\section{MATERIALS AND METHODS}

The medical records and autopsy findings of all medicolegal postmortem examinations with positive findings at Jos University Teaching Hospital, Jos, Nigeria between January 1996 and December 2003 form the basis of this study. All the medicolegal autopsies without identifiable causes of death were excluded. The autopsies were carried out by consultant pathologists with interest in forensic pathology. In cases of suspected poisoning, tissues were sent for forensic toxicology at the National Forensic Laboratory at Kaduna, Nigeria. The medical records, the manner of death, toxicology reports and postmortem findings were all entered into the coroner's inquest form and the computer database of the Department of Pathology by the pathologists who performed the autopsies. The autopsies were performed using a standard format.
Their demographic features, clinical data including the manner of death and the causes of death confirmed at postmortem were statistically analysed using the Epi Info version 2002 (CDC, Atlanta, GA).

\section{RESULTS}

A total of 279 cases of medicolegal autopsies with positive findings at postmortem were recorded during the period of this study. This represented $89.1 \%$ of the 313 autopsy examinations performed within the same period. There were 227 males against 52 females with a male: female ratio of 4.4:1 and their ages ranged between two and 74 years with a mean of $34.7 \pm 8.2$ years. Children aged $<15$ years were eighty one $(29 \%)$ and were distributed as follows: eleven (3.9\%) children were in the $0-5$ years bracket, twenty three $(8.2 \%)$ were aged between six to ten years while forty seven (16.8\%) were between 11-15 years. Adults aged above fifteen years were 198 (71\%). Accidental deaths were 143 $(51.3 \%)$, homicides $101(36.2 \%)$ and sudden natural deaths-thirty five (12.5\%) (Table 1$)$. Road traffic accidents were responsible for $76.2 \%$ of all accidental deaths, followed by plane crash in $9.1 \%$ and burns in $5.6 \%$ (Table 2). There were forty eight children constituting $33.6 \%$ of the accidental deaths and half of them were pedestrians at the time of accident. The male: female ratio of deaths from road traffic accidents was 3:1 with mean age of twenty four years. Of the accidental deaths, $47 \%$ died from abdominal injuries, 30\% from chest injuries, $16 \%$ from cranio-cervical injuries and $7 \%$ from multiple fractures. Out of the 101 cases of homicide, there were 95 males and six females with a ratio of 15.8:1 . Violent ethnic and religious crises among the civilian population were responsible for forty eight $(47.5 \%)$, armed robbery in twenty eight $(27.7 \%)$ and physical assaults in twenty (19.8\%) cases (Table 3). There were twenty eight children making up $27.7 \%$ of the homicide cases; fifteen (14.8\%) of them were killed in ethnic/religious communal clashes. Chest injuries claimed $54 \%$ of the homicides, abdominal injuries $36 \%$ and cranio-cervical injuries in $10 \%$. Cardiovascular deaths were responsible for twenty two $(62.8 \%)$ cases of all sudden natural deaths while pulmonary infections were responsible for six $(17.1 \%)$ cases (Table 4$)$ among whom were three (11.4\%) children. Of the cardiovascular deaths, the male: female ratio was $6: 1$; ten $(45.5 \%)$ cases died of 
hypertensive heart failure, seven $(31.8 \%)$ as a result of cerebrovascular accidents, three $(13.6 \%)$ cases were due to pulmonary embolism secondary to cardiac arrhythmia; two (9\%) due to myocardial infarction - one slumped and died at his workplace after an altercation while the other on medication for dysrrhythmia died during intercourse.

Exclusion criteria: No obvious cause of death could be identified in twenty three others cases which formed $7.6 \%$ of all the medicolegal autopsies during the period and this group was excluded.

Table 1

Manner of death

\begin{tabular}{lrrrr}
\hline Event & M & F & Total & $(\%)$ \\
\hline Accidental deaths & 103 & 40 & 143 & 51.3 \\
Homicide & 95 & 6 & 101 & 36.2 \\
Sudden natural & 29 & 6 & 35 & 12.5 \\
death & & & & \\
\hline Total & 227 & 52 & 279 & 100 \\
\hline
\end{tabular}

Table 2

Causes of accidental deaths

\begin{tabular}{lrc}
\hline Event & No. & $(\%)$ \\
\hline Road traffic accident & 109 & 76.2 \\
Plane crash & 13 & 9.1 \\
Burns & 8 & 5.6 \\
Drowning & 7 & 4.9 \\
Electrocution & 6 & 4.1 \\
\hline Total & 143 & 100 \\
\hline
\end{tabular}

Table 3

Circumstances of homicide

\begin{tabular}{lrc}
\hline Event & No. & $(\%)$ \\
\hline Ethno-religious crisis & 48 & 47.5 \\
Armed robbery & 28 & 27.7 \\
Physical assault & 20 & 19.8 \\
Burns & 5 & 5.9 \\
\hline Total & 159 & 100 \\
\hline
\end{tabular}

Table 4

Causes of sudden natural deaths

\begin{tabular}{lrc}
\hline Event & No. & $(\%)$ \\
\hline Cardiovascular & 22 & 63 \\
Pulmonary infections & 6 & 17 \\
Liver cirrhosis & 7 & 20 \\
\hline Total & 35 & 100 \\
\hline
\end{tabular}

\section{DISCUSSION}

The principal finding in this study was that road traffic accidents, homicide and armed robbery constituted the reasons for majority $(66 \%)$ of medicolegal autopsies in this tropical environment. We also found out that medicolegal reasons were the main indications for relatives of the deceased acceding to postmortem in this environment as medicolegal autopsies were responsible for $96 \%$ of all the postmortem examinations during the study period. The significance of this finding is that $66 \%$ of these deaths were preventable and could be controlled by instituting well-structured safedriving culture and sustainable road maintenance policies as well as security for life and property in this tropical environment. North Central Nigeria is a geo-political entity spanning several jurisdictions with a population of over 10 million.

Out of a total of 279 medicolegal autopsies with identified causes of death during the period of this study, there were about five fold incidence in males than females. Children made up a third and majority of the children were in the 10-15 years bracket. Accidental deaths were responsible for $51 \%$ of the cases, homicides $36 \%$ and sudden natural deaths $13 \%$. This is slightly at variance with the earlier work of Rafindadi (3) in this region where homicide was the commonest indication for medicolegal autopsies but in keeping with the work of Diegbe and co-workers (11) in southern Nigeria. This shows that even in the same country, there are variations in the manner of death in cases in which postmortem examinations are performed for the purposes of the law. Road traffic accidents were responsible for the majority $(76 \%)$ of accidental deaths - a finding consistent with the report of other workers in Nigeria $(3,5,11)$ and elsewhere $(6-9,15)$. This high rate is attributed to bad roads, reckless driving and increasing rate of drunkdriving. There was a preponderance of young active 
males in deaths from road traffic accidents -the young, mobile and active segment of the society who contribute enormously to the economy. This pattern had been identified decades ago by Adeloye and Odeku (16) and had continued to be reported in recent works on road traffic accidents in this environment $(5,11,17)$. A grim picture is emerging as the incidence of road traffic accidents is increased by the recent use of motorcycles as commercial means of transportation without protective crash helmets as well as night trips by commercial long-distance buses. The implication of this is that significant improvement has not been recorded on our road maintenance and safe-driving culture. Children made up about a third of all accidental deaths and half of them were pedestrians at the time of their accident. The high incidence of accidental deaths in children as a result of road traffic accidents had been highlighted by other workers on this subject $(5,9,18,19)$.

Homicide was responsible for more than one third of the medicolegal autopsies in this study affecting mainly the young and the male gender. A quarter of the homicide deaths were children and more than half of them were killed in violent ethnic/ religious communal clashes in our civilian population. The recent upsurge in using violent means to settle communal disputations has increased the incidence of homicide in our environment. This observation was shared by Rafindadi (3) in this region. During the communal clashes, no age, gender or weapon is spared so long as maximum damage is inflicted on the opposing camp; the upsurge in arrow injuries, is as a result of frequent communal clashes. Public enlightenment, respect for the rule of law and sustainable security for life and property would reduce the incidence as well as the severity of communal violence.

Armed robbery was responsible for a quarter of homicide deaths in this study. It is a systemic problem in Nigeria and it is being fuelled by unemployment and communal crises. All manners of weapons available to the robbers are employed from bow and arrows (22) to high velocity riffles (23). In sum, abdominal and chest injuries were the causes of death in $87 \%$ of accidental death while $90 \%$ of homicides died from the same injuries. The implication of this is that if skilled manpower and resources required to promptly and effectively manage chest and abdominal injuries are located along the major highways, a significant number of these deaths could have been prevented.

About two thirds of all sudden natural deaths in this report were cardiovascular in origin and more than $80 \%$ of them were males. The cardiovascular causes of death were hypertensive heart failure in $45 \%$, and cerebrovascular accident as a result of hypertension in $32 \%$. Hypertension therefore, was responsible for more than $75 \%$ of cardiovascular deaths in this study. This significant finding implies that these deaths could have been prevented by adequate blood pressure control - a point that should be emphasized in the epidemiology and prevention of non-communicable diseases in our environment. Myocardial infarction is the commonest cause of cardiovascular deaths in the developed countries $(9,13,14)$ but it was responsible for $9 \%$ of cardiovascular deaths in this study. Similar low incidence of myocardial infarction in medicolegal autopsies had been recorded in another developing country (15). Recreational activities have been reported to precipitate death in patients with myocardial infarction (24). One of the cardiovascular deaths in this report, a middle-aged man on medication for cardiac arrhythmia, died during sexual intercourse. Sudden death during sexual intercourse had been reported by Parzeller and colleagues (25) in their series.

There was no case of suicide in this series. The low rate of suicide in medicolegal autopsies in this environment had been highlighted by Rafindadi (3). This is in contrast to the high rate of suicide in medicolegal autopsies in industrialised nations (9). Genetic causes for the tendency to commit suicide have been reported $(26,27$ )and the World Health Organisation has instituted guidelines on suicide behaviour prevention (10).

About $96 \%$ of autopsies performed in this centre within the period of study were for medicolegal reasons when negative autopsies were included. This means that only about $4 \%$ of the postmortem examinations were conducted at the request of the relatives of the deceased and not at the instance of the coroner. This low rate of postmortem examinations was as a result of perceived cultural and religious barriers; this trend had been corroborated by other workers $(3,28)$ in this country. Low autopsy rate denies the relatives of the deceased the opportunity to confirm the cause of death and deprives them of the ability to determine family trends in preventable diseases. Properly conducted counselling has been shown to improve the relatives' acceptance and collaboration toward forensic autopsy (29). 


\section{ACKNOWLEDGEMENT}

The authors acknowledge the support of the staff of the Jos University Teaching Hospital Mortuary.

\section{REFERENCES}

1. Laws of Nigeria on birth and death registration; cap 20 of 1948.

2. Coroner's Law of Northern Nigeria; Cap. 27 of 1963.

3. Rafindadi A.H. A study of sudden medicolegal deaths in Zaria. Nigerian Post Grad. Med. J. 1998; 5: 28-30.

4. Nwosu S.O. and Odesanmi W.O. Pattern of homicides in Nigeria. The IIe-Ife experience. Nigerian Med. Pract. 1994; 28: 16-17.

5. Etebu E.N. and Ekere A.U. Paediatric accidental deaths in Port Harcourt Teaching Hospital, Port Harcourt, Nigeria. Nigerian J. Med. 2004; 13: 140-143.

6. Otieno T., Woodfield J.C., Bird P. and Hill A.G. Trauma in rural Kenya. Injury. 2004; 35: 1228-1233.

7. Meel B.L. Incidence and patterns of violent and/or traumatic deaths between 1993 and 1999 in Transkei region of South Africa. J. Trauma. 2004; 57: 125-129.

8. Meet B.L. Pine-hospital and hospital traumatic deaths in the former homeland of Transkei, South Africa. J. Clin. Forensic Med. 2004; 11: 6-11.

9. Kochanek K.D., Murphy S.L., Anderson RN. and Scott C. Deaths: Final data for 2002. Natl. Vital Stat. Rep. 2004; 53: 1-115.

10. Bertolote J.M. and Fleischmann A. Suicide behavior prevention: WHO perspectives on research. Amer. J. Med. Genet. C. Semin. Med. Genet. 2005; 133: 8-12.

11. Diegbe I.T., Ideowor P.E. and Igbokwe U.O. Autopsy audit in a Teaching Hospital in Nigeria: The Benin experience. West Afr. J. Med. 1998; 17: 213-216.

12. Olasode B.J. and Odesanmi W.O. The hospital autopsy: Halting the decline. Nigerian Post Grad. Med. J. 1998; 5: 37-39.

13. Murai T., Baba M., Ro A., Murai N., Matsuo Y., Takada A. and Saito K. Sudden death due to cardiovascular disorders: a review of the studies on the medicolegal cases in Tokyo. Keio J. Med. 2001; 50: 175-181.

14. Perez-Carceles M.D., Noguera J., Jimenez J.L., Martinez P., Luna A. and Osuna E. Diagnostic efficiency of biochemical markers in diagnosis of postmortem ischaemic heart disease. Forensic Sci. Int. 2004; 142: 1-7.

15. Escoffery C.T. and Shirley S.E. Causes of sudden natural death in Jamaica: A medicolegal (coroner's) autopsy study from the University Hospital of the West Indies. Forensic Sci. Int. 2002; 129: 116-121.

16. Adeloye A. and Odeku E.L. The pattern of road traffic accidents seen at the University College Hospital, Ibadan, Nigeria: A preliminary study. West Afr. Med. J. 1970; 19: 153-157.

17. Rafindadi A.H. Fatal road traffic accidents in Zaria, Nigeria. Nigerian Med. J. 2000; 38: 27-29.

18. Meel B.L. Mortality of children in the Transkei region of South Africa. Amer J. Forensic Med. Pathol. 2003; 24: 141-147.

19. Bartsch C., Risse M., Nagelmeier I.E. and Weiler G. Deaths in pine-school and school age: A retrospective analysis from a medicolegal point of view. Arch. Kiniminol. 2004; 214: 30-36.

20. Ugwu B.T., Yiltok S.J., Dakum N.K., Ode G.O. and Ameh V.Y. An unusual chest impalement. West Afr. J. Med. 1998; 17: 55-57.

21. Madziga A.G. Arrow injuries in North East Nigeria. West Afr. J. Med. 2003; 22: 106-109.

22. Ogunleye A.O.A., Odeleye A.O., Ayodele K.J., Usman M.O. and Shokunbi M.T. Arrow injury to the skull base. West Afr. J. Med. 2004; 23: 94-96.

23. Yinusa W. and Ogrima M.O. Extremity gunshot injuries in civilian practice: the National Orthopaedic Hospital Igbobi experience. West Afr. J. Med. 2000; 19: 312-316.

24. Fornes P. and Lecomte D. Pathology of sudden death during recreational sports activity: An autopsy study of 31 cases. Amer. J. Forensic Med. Pathol. 2003; 24: 9-16.

25. Parzeller M., Raschka C. and Bratske H. Sudden cardiovascular death during sexual intercourse results of a legal medicine autopsy study. Z. Kardiol. 1999; 88: 44-48.

26. Wasserman D., Geijer T., Rozanov V. and Wasserman J. Suicide attempt and basic mechanisms in neural conduction: Relationships to the SCN8A and VAMP4 genes. Amer. J. Med. Genet. B. Neuropsychiatr. Genet. 2005; 133: 116-119.

27. Marusic A. History and geography of suicide: Could genetic risk factors account for the variation in suicide rates? Amer. J. Med. Genet. C. Semin. Med. Genet. 2005; 133: $43-44$

28. Igbokwe U.O. and Diegbe I.T. Knowledge and attitude of family members to autopsy at UBTH Benin City, Nigeria. Nigerian Post-grad. Med. J. 1998; 5: 163-166.

29. Plattner T., Scheurer E. and Zollinger U. The response of relatives to medicolegal investigations and forensic autopsy. Amer. J. Forensic Med. Pathol. 2002; 23: 345-348. 